\title{
Temporal Analysis of a Case Series of Leprosy Patients From a Low Endemic Area in Brazil and the Magnitude of Disability
}

Cléa Maria da Costa Moreno', Isabelle Campos de Azevedo , Fernanda Darliane Tavares de Luna1, Rita de Cássia Lira da Silva', Jéssica Valeska Herculano Lima1, Luisa Alves Pereira de Aquino', Angela Toepp ${ }^{2}$, Selma Maria Bezerra Jeronimo ${ }^{3}$, Allyne Fortes Vitor ${ }^{1}$, Viviane Euzébia Pereira Santos ${ }^{1}$, Marcos Antonio Ferreira Júnior ${ }^{1}$

\section{Abstract}

Leprosy is an infectious disease caused by Mycobacterium leprae infection. The incubation period after the primary infection can be as long as decades. This bacterium has a tropism for macrophages and Schwann cells and as result neuropathies are frequent. The state of Rio Grande do Norte in northeastern Brazil has areas of low and high endemicity for leprosy. The aim of this study was to analyze a leprosy time series from Rio Grande do Norte, from 2005 to 2014, based on data provided by the Notifiable Diseases Information System from the State Secretariat of Health. This was a quantitative, descriptive and analytical study. We considered variables such as sex, age, clinical form, operational classification and disability grade at diagnosis. There were 3,426 cases of leprosy reported of which 1,781 were females (52\%). Of those patients, $29 \%$ presented disability at diagnosis. The high level of disability in patients along with the lack of information regarding disability levels indicates the need for more effective measures, with early diagnosis to decrease morbidity as leprosy still remains as a serious public health problem.

\section{Introduction}

Leprosy is an infectious disease caused by Mycobacterium leprae infection [1]. This bacterium presents a slow growth but leads to disease development that can be accompanied by the development of severe disability [2]. M. leprae has a particular tropism for Schwann cells,
1 Departamento de Enfermagem, Centro de Ciências da Saúde, Universidade Federal do Rio Grande do Norte, Natal/ RN, Brasil.

2 University of lowa College of Public Health, lowa, United States of America.

3 Departamento de Bioquímica, Centro de Biociências, Universidade Federal do Rio Grande do Norte, Natal/RN, Brasil.

\section{Contact information:}

Marcos Antonio Ferreira Júnior.

Address: Universidade Federal do Rio Grande do Norte, Centro de Ciências da Saúde, Departamento de Enfermagem. Avenida Salgado Filho, S/N, Lagoa Nova, Natal, RN, Brasil. CEP: 59078970.

Đmarcos_nurse@hotmail.com

Keywords

Leprosy; Epidemiology;

Disease Prevention. 
with frequent neuropathy, which is a main cause of disability. The neuropathies are usually mixed, with damage to sensory, motor and autonomic nerve fibers, resulting in deformities and permanent disability $[3,4]$.

It is essential to conduct neurological assessment throughout treatment, which is usually recommended at the beginning, during, and at the end of treatment, or based on whenever clinical signs or symptoms of neuritis develop [5]. The course of the disease can be measured through the assessment of the level of disability in the patient. Clinical manifestations of the neuritis can be estimated by the severity of the pain, nerve hypersensitivity, edema, sensory and motor functions. However, the neuritis may evolve with no pain, which is termed silent neuritis, which can be identified during the neurological assessment $[3,6,7]$.

Although there is effective free available treatment for leprosy, it still remains a major public health issue in many areas of the world, including Brazil, which is the country with the second highest number of new cases detected each year $[8,9]$. Understanding the epidemiology and identifying clustering of disease is essential to develop intervention measures.

In Brazil's northeast region leprosy has persisted with a high number of cases over the years, but some of northeastern states have a level of endemicity considered within the standards of elimination, such as the State of Rio Grande do Norte (RN) [10]. This state showed a significant reduction in the prevalence of leprosy with a current rate of $0.74 \mathrm{ca}$ ses/10,000 inhabitants. However, within the state, there are areas of high endemicity with new case detection greater than 40 per 100,000 [11-13].

Thus, the state of Rio Grande do Norte has been heterogeneous in the level of leprosy case detection over the years. While there are municipalities that do report cases, others are considered hyperendemic and thus have been targeted as locations of high priority by the Brazilian Ministry of Health [14]. In general, leprosy is a silent disease that re- quires effective participation of health staff at the community level to allow for early diagnosis and prompt administration of treatment.

Rio Grande do Norte, similar to many other Brazilian states, has referral centers for leprosy diagnosis. Of concern, has been the increase in case detection in children under 15 years of age, with grade II disability at diagnosis, indicating a very late identification. The aim of this study was to analyze a time series of leprosy cases in Rio Grande do Norte, northeastern Brazil, between 2005-2014, based on data provided by the Notifiable Diseases Information System, from the State Secretariat of Health.

\section{Methods}

\section{Study area}

The State of Rio Grande do Norte is located in Northeast Brazil and has 167 municipalities, with an estimated population in 2015 of 3,442,175 inhabitants living in an area of $52,811.126 \mathrm{~km}^{2}$. Its population density is 59.99 inhabitants $/ \mathrm{km}^{2}$ with per capita monthly income of $\$ 248.00$. The state capital is Natal, located on the state's eastern coast [15].

\section{Source of data}

This is a descriptive and analytical study, which was based on cases of leprosy froOm the State of Rio Grande do Norte, reported to the Minister of Health between August 2005 to October 2014.

\section{Statistical Analysis}

Graphical analyzes and calculations of prevalence as well as analysis of differences in sex, age, clinical form, operational classification, and degree of disability were completed using Excel (Microsoft, Redmond, WA), R version 3.3.1 "Bug in Your Hair" statistical software with epiR package, and Graph Pad Prism version 6.05 (Graph Pad Software Inc., La Jolla, CA). Pearson chi-squared test was used to compare clinical forms of diseases in males and 
females. One-way ANOVA with Tukey's multiple comparisons test was utilized to assess differences in the types of clinical forms and degree of disability within the study.

\section{Ethical considerations}

The protocol was assessed and approved by the Universidade Federal do Rio Grande do Norte Ethical Committee (CEP-UFRN) and by the Brazilian National Ethical Committee (CONEP/CNS/Ministério da Saúde, Brasília). All participants or their legal guardians signed informed consent forms prior to sample collection.

\section{Results}

A total of 3,426 cases of leprosy were diagnosed in the state of Rio Grande do Norte between 2005 and 2014 (Figure 1). There was were slight variations from the average number of leprosy cases identified each year in 2005, 2007, and 2010 but the remaining years were more homogeneous in detection rates, as shown in Figure 1.

Of the 3,426 cases, 1,781 were females (52\%) (Figure 2), with no significant difference between the number of males and females with leprosy throughout the study ( $p$-value $=0.5051$ ( $\mathrm{Cl}:-28.41$, 55.61). When controlling for sex, there was a statistically significant difference in the number of cases of leprosy based on age. There were more cases of leprosy among individuals 15 years of age or older compared to 0-14 years of age in both males and females. (males p-values: <0.0001) (females pvalues: <0.0001).

When analyzing clinical forms of disease it was found that females were twice as likely as males to present with indeterminate or tuberculoid forms of disease (OR:2.03, p-value $=<0.0001$ and OR:2.14 $p$-value $=<0.0001$, respectively) (Table 1 \& Figure 3). Males were more likely to present with Dimorphous or Lepromatous forms of disease (OR: 1.56 $p$-value $=<0.0001$ and OR: 2.89 p-value $=<0.0001$,
Figure 1: Leprosy cases reported for the State of Rio Grande do Norte, Brazil from 2005 to 2014. Natal/RN. Straight line represents average number of leprosy cases across time series (342.6). Total number of cases across all 10 years was 3,426.

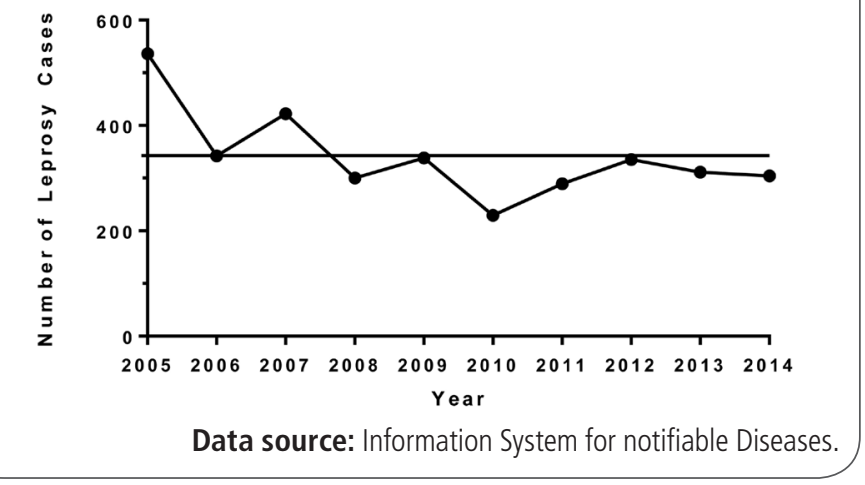

Figure 2: Cases of Leprosy reported in the State of Rio Grande do Norte, Brazil from 2005 to 2014. Natal/RN based on sex.

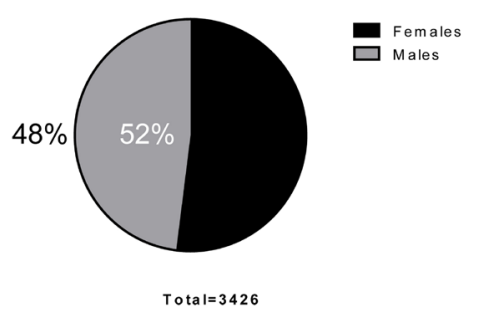

Data source: Information System for notifiable Diseases.

Figure 3: Distribution of Clinical Forms of Leprosy Based on Sex in the State of Rio Grande do Norte from 2005-2014. I=Indeterminate, T: Tuberculoid, D: Dimorphous, L: Lepromatous, ND: Not Determined. a) is the distribution of clinical forms of leprosy in males; b) is the distribution of clinical forms in females.
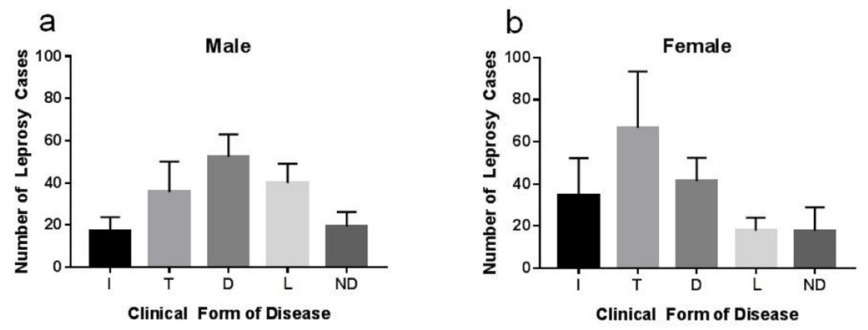

Data source: Information System for notifiable Diseases. 
Table 1. Distribution of clinical forms of Leprosy based on sex.

\begin{tabular}{|l|c|c|c|c|c|c|}
\hline \multirow{2}{*}{$\begin{array}{l}\text { Clinical } \\
\text { Form }\end{array}$} & \multicolumn{2}{|c|}{ Male } & \multicolumn{2}{c|}{ Female } & Total & P-Value \\
\cline { 2 - 7 } & $\mathrm{N}$ & $\%$ & $\mathrm{~N}$ & $\%$ & & \\
\hline Indeterminate & 172 & 33.3 & 344 & 66.7 & 516 & $<0.0001$ \\
\hline Tuberculoid & 357 & 34.9 & 667 & 65.1 & 1024 & $<0.0001$ \\
\hline $\begin{array}{l}\text { Dimorphous } \\
\text { Lepromatous }\end{array}$ & 524 & 55.9 & 413 & 44.1 & 937 & $<0.0001$ \\
\hline $\begin{array}{l}\text { Not } \\
\text { Determined }\end{array}$ & 192 & 51.9 & 178 & 49.4 & 360 & 0.1272 \\
\hline Total & 1645 & & 1781 & & 3426 & \\
\hline
\end{tabular}

Table 2. Distribution operational classification of leprosy cases based on sex.

\begin{tabular}{|l|c|c|c|c|c|c|}
\hline $\begin{array}{l}\text { Operational } \\
\text { Classification }\end{array}$ & \multicolumn{2}{|c|}{ Male } & \multicolumn{2}{|c|}{ Female } & Total & $\%$ \\
\hline Multibacillary & 1074 & 65.3 & 695 & 39.0 & 1769 & 51.6 \\
\hline Paucibacillary & 569 & 34.6 & 1082 & 60.8 & 1651 & 48.2 \\
\hline Not Documented & 2 & 0.1 & 4 & 0.2 & 6 & 0.2 \\
\hline Total & 1645 & & 1781 & & 3426 & \\
\hline
\end{tabular}

respectively). Furthermore, when controlling for sex it was seen that the dimorphous form of disease was more common than any other form of disease within males and Tuberculoid form within females. While it was not statistically significant there were slightly higher odds of not having a clinical form reported for male patients compared to female patients (OR: 1.19 p-value $=0.1272$ ).

Additionally we found that, $51.7 \%$ of the cases were Multibacillary and of these $60.7 \%$ were males, as shown in Table 2 . When analyzed the mean number of multibacillary cases among males was higher than the mean number of paucibacillary cases $(p$-value $=<0.001)$. Furthermore, in females there was a higher number of paucibacillary cases versus multibacillary ( $p$-value 0.0096).

The degree of disability measured at the time of diagnosis, of the 3,426 cases, was as follows: 1,916 (59.6\%) had grade 0 of disability, 689 (20.1\%) presenting with grade I, 301 (8.1\%) presenting with grade II, and 520 (15.1\%) did not have available data on disability level (Figure 4). Statistical analysis showed that grade 0 was more common than grades I and II (p-value $=<0.0001$ and $<0.0001$, respectively). Furthermore, while the difference was statistically significant grade I was slightly more common than grade II ( $p$-value 0.0811).

Figure 4: Distribution of Disability Grades of Leprosy in the State of Rio Grande do Norte from 2005-2014. 0=Grade 0, I=Grade 1, $\mid=$ =Grade 2, ND=Not Determined.

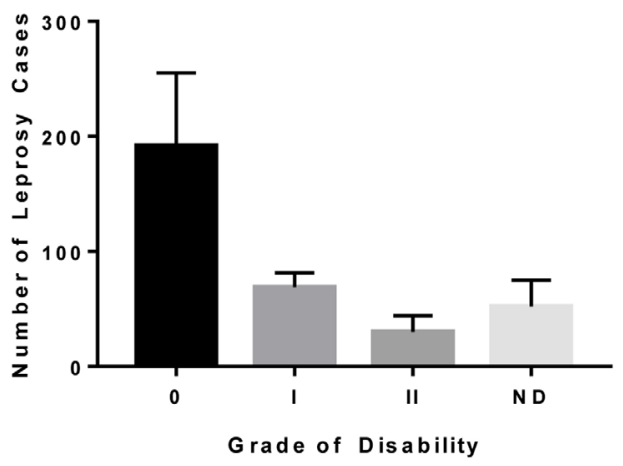

Data source: Information System for notifiable Diseases.

\section{Discussion}

Brazil is the country with the second highest number of new cases reported for leprosy $[16,17]$. The disease is clustered within low and high endemic areas. The state of Rio Grande do Norte is considered a low endemic area [10], however, as previously reported $[10,13]$, there are municipalities with high rates of case detection. In our study, we observed variations in the number of cases reported, which might be associated with active case searches, such as those in Mossoró [11-13].

In the state of Rio Grande do Norte, children under 15 corresponding to $15 \%$ of all cases. Leprosy affects people of all ages [18]. Leprosy in children is usually reported in areas with greater endemicity of the disease [8]. In 2011, the Brazilian Ministry of Health recorded 33,955 new cases of leprosy, 
of which 2,420 (7.12\%) were diagnosed in children under 15 years of age. In the state of Pará, in the Amazonas region, in 2011, the overall rate of new cases in children under 15 years was 18.29/100,000 inhabitants. In Brazil, an annual detection rate above $10 / 100,000$ is considered hyperendemic [19]. Therefore, our observations and those from other parts of Brazil signal to the need to deliver active search within the areas of high endemicity to diagnosis cases at earlier stages.

The distribution by sex observed in this study is similar to other places in Brazil, with disease affecting both sexes, but women tend to present as paucibacillary, with indeterminate or turberculoid forms [20]. Multibacillary cases are the source of infection and maintenance of the endemicity. However, after a few weeks of antibiotic therapy there is a significant decrease in transmission, because the first doses of medication inactivate bacilli and make them unable to infect others [21, 22].

A study in Brazil's southeastern region of cities found that professionals in primary health care had little knowledge about the disease, which hampered the organization of municipal programs for the control and prevention of disease. This lack of knowledge resulted in inadequate approaches and impresses the need for training

Regarding the indicator "assessment of the degree of disability", which should be analyzed at diagnosis, we found that there was a lack of initial assessment in $15 \%$ of leprosy cases. This fact arouses some concern since it could result in more physical disability. Neurological assessment defines the degree of disability due to the risk of the development of irreversible neurological damage. The particular tropism that $M$. leprae has for the nerve fibers is a detrimental factor that can lead to neuropathy. When the peripheral nerves are affected by bacilli, there is a loss of thermal and tactile sensitivity, and deep painful sensitivity. The response to inflammation can be varied from minor responses in functional changes to the granulomatous infiltra- tion of the entire neural parenchyma that can lead to the destruction of peripheral nerves and loss of function $[2,4]$. Therefore, these results emphasize the need for neurological assessment of all patients affected by leprosy.

Often the neuritis is accompanied by intense pain, nerve hypersensitivity, edema, sensory and motor function. However, these phenomena can develop without pain as in the case of silent neuritis $[3,23]$. When there is no pain or nerve hypersensitivity, the possibility of changes in sensitivity is a signal to aware. In order to monitor the evolution of complications, it is recommended frequent neural assessment, serious nerve damage can occur and can severely compromise the activities of daily life for patients [2]. Thus, this assessment at the beginning of treatment sets allows for the assessment of sensitivity changes, which are an alarming sign of nerve damage, even if the person does not present any complaints $[2,4]$.The main action plan for the Ministry of Health, to achieve low endemic levels of leprosy, is based on the organization of a network with integration of control strategies and early detection of new cases. Emphasis on treatment with multidrug therapy, prevention of disabilities and surveillance of household contacts are encouraged $[24 ;, 5]$. The system also includes the monitoring of patients in primary health care settings, according to each region or district health system, and maintenance/specialization of care in specialized networks in the secondary and tertiary levels when necessary [26].

\section{Conclusions}

The data demonstrate the need for the development of many actions in order to control leprosy. It is important to note the heterogeneous distribution of the disease in the municipalities of this northeastern Brazilian state, because it is a silent disease in its early stages. This feature reinforces that activities should be carried out in accordance to the region 
endemicity, since the incidence of leprosy varies greatly within the Brazilian regions. Thus, the work needs to be intensified in priority municipalities. This study contributes to a better understanding of endemic disease, in order to direct the actions in state such as RN, which could be a model for intervention. It is true that health education carried out through educational campaigns should be a constant activity, in addition to professional training. The high turnover of health professionals is also a consistent problem and therefore the authorities should always be vigilant and prepared for this phenomenon, with effective plans to overcome this obstacle.

It is possible to conclude the state still cannot control leprosy and needs more effective strategies for combating the disease. The healthcare professional must be alert, and intensify surveillance around areas that have reported leprosy. It should be emphasized that it is essential to have the support of all professionals, managers, and people affected by leprosy, in order to gain full control of this disease.

\section{References}

1. Ridley DS, Jopling WH. A classification of leprosy for research purposes. Lepr Rev. 1962 Apr; 33:119-28.

2. Richardus JH, Finlay KM, Croft RP, Smith WC. Nerve function impairment in leprosy at diagnosis and at completion of MDT: a retrospective cohort study of 786 patients in Bangladesh. Lepr Rev. 1996 Dec; 67(4):297-305.

3. Van Brakel WH, Khawas IB. Silent neuropathy in leprosy: an epidemiological description. Lepr Rev. 1994 Dec; 65(4):350-60.

4. Van Brakel WH, Nicholls PG, Das L, Barkataki P, Suneetha SK, Jadhav RS, et al. The INFIR Cohort Study: investigating prediction, detection and pathogenesis of neuropathy and reactions in leprosy. Methods and baseline results of a cohort of multibacillary leprosy patients in north India. Lepr Rev. 2005 Mar; 76(1):14-34.

5. Faber WR. Comment on 'reports from the workshop on the neurologically impaired foot. Lepr Rev. 2003 Mar; 74(1):84-5.

6. Scollard DM, Martelli CM, Stefani MM, Maroja MF, Villahermosa $L$, Pardillo $F$, et al. Risk factors for leprosy reactions in three endemic countries. Am J Trop Med Hyg. 2015 Jan; 92(1):108-14.
7. Siddiqui MR, Moreira AL, Negesse Y, Taye GA, Hanekom WA, Haslett PA, et al. Local nerve damage in leprosy does not lead to an impaired cellular immune response or decreased wound healing in the skin. J Infect Dis 2002 Jul 15;186(2):260-5.

8. Global leprosy: update on the 2012 situation. Wkly Epidemiol Rec. 2013 Aug; 88(35):365-79.

9. De Oliveira DT, Bezerra MM, de Almeida JA, Duthie M, Reed S, de Jesus AR. Neurological disability in leprosy: incidence and gender association in Sergipe, Brazil. Geospat Health. 2012 Sep;6(3):S125-S129.

10. Ministério da Saúde (BR). III Carta de eliminação da hanseníase -Rio Grande do Norte- janeiro, 2005. Brasília: Ministério da Saúde; 2005. Available from: http://portal.saude.gov.br/portal/ arquivos/pdf/carta3 rn.pdf.

11. De Souza Dias MC, Dias GH, Nobre ML. The use of Geographical Information System (GIS) to improve active leprosy case finding campaigns in the municipality of Mossoro, Rio Grande do Norte State, Brazil. Lepr Rev. 2007 Sep;78(3):261-9.

12. Moura ML, Dupnik KM, Sampaio GA, Nobrega PF, Jeronimo AK, do Nascimento-Filho JM, et al. Active surveillance of Hansen's Disease (leprosy): importance for case finding among extradomiciliary contacts. PLoS Negl Trop Dis. 2013; 7(3):e2093.

13. Nobre ML, Dupnik KM, Nobre PJ, Freitas De Souza MC, Duppre NC, Sarno EN, et al. Human migration, railways and the geographic distribution of leprosy in Rio Grande do Norte State-Brazil. Lepr Rev. 2015 Dec;86(4):335-44.

14. Ministério da Saúde (BR). Sistema nacional de vigilância em saúde: relatório de situação: Rio Grande do Norte / Ministério da Saúde 5. Ed. Brasília: Ministério da Saúde; 2011.

15. IBGE. Instituto Brasileiro de Geografia e Estatística. Rio Grande do Norte. Estimativas de população para $1^{\circ}$ de julho de 2015 Available from: http://www.ibge.gov.br/home/estatistica/ populacao/estimativa2015/estimativa tcu.shtm

16. Penna ML, Penna GO. Leprosy frequency in the world, 19992010. Mem Inst Oswaldo Cruz. 2012 Dec; 107 Suppl 1:3-12.

17. Rodrigues Junior IA, Gresta LT, Noviello ML, Cartelle CT, Lyon S, Arantes RM. Leprosy classification methods: a comparative study in a referral center in Brazil. Int J Infect Dis. 2016 Apr; 45:118-22.

18. Scollard DM, Martelli CM, Stefani MM, Maroja MF, Villahermosa $\mathrm{L}$, Pardillo F, Tamang KB. Risk factors for leprosy reactions in three endemic countries. Am. J. Trop. Med. Hyg. 2015; 92: 108114.

19. Ministério da Saúde (BR). Sistema de Informação de Agravos de Notificação. Available from: http://dtr2004.saude.gov.br/ sinanweb/tabnet/dh?sinannet/hanseniase/bases/Hansbrnet.def

20 Ramos JM, Martinez-Martin M, Reyes F, Lemma D, Belinchon I, Gutierrez F. Gender differential on characteristics and outcome of leprosy patients admitted to a long-term care rural hospital in South-Eastern Ethiopia. Int J Equity Health. 2012; 11:56. 
21. Ghosh A, Panda S. Current trends in leprosy transmission in eastern India in the era of 12-month multi-drug treatment: a hospital-based retrospective study. Int. J. Dermatol. 2014; 53 : 462-465.

22. Sarno EN, Duppre NC, Sales AM, Hacker MA, Nery JA, de Matos HJ. Leprosy exposure, infection and disease: a 25-year surveillance study of leprosy patient contacts. Mem. Inst. Oswaldo Cruz 2012; 107:1054-9.

23. Richardus JH, Nicholls PG, Croft RP, Withington SG, Smith WC. Incidence of acute nerve function impairment and reactions in leprosy: a prospective cohort analysis after 5 years of follow-up. Int J Epidemiol. 2004 Apr; 33(2):337-43.

24. Carvalho APM, Fabri ACOC, Lanza FM, Lopes FN, Lana FCF. Integration of leprosy control activities from the perspective of health professionals. Rev enferm UFPE on line. 2015; 9(1):11420.

25. Lanza FM, Vieira NF, Oliveira MMC, Lana FCF. Instrument for evaluating the actions of leprosy control in Primary Care. Rev Bras Enferm. 2014; 67(3):339-46.

26. Nery JS, Pereira SM, Rasella D, Penna ML, Aquino R, Rodrigues LC, et al. Effect of the Brazilian conditional cash transfer and primary health care programs on the new case detection rate of leprosy. PLoS Negl Trop Dis. 2014 Nov; 8(11):e3357.

Publish in International Archives of Medicine

International Archives of Medicine is an open access journal publishing articles encompassing all aspects of medical science and clinical practice. IAM is considered a megajournal with independent sections on all areas of medicine. IAM is a really international journal with authors and board members from all around the world. The journal is widely indexed and classified Q1 in category Medicine. 